\title{
EL VIDEOJUEGO COMO MATERIAL EDUCATIVO: LA ODISEA
}

\author{
Belén Mainer Blanco
}

Doctoranda por la Universidad Complutense de Madrid y redactora de CNN+

\section{Resumen}

La investigación se basa en la función educativa que pueden cumplir los videojuegos, un campo que consideramos inexplorado por tres motivos principalmente: su reciente incorporación, su impopularidad educativa (el rechazo el videojuego como herramienta de aprendizaje y considerado, por el contrario, como una distracción), y la incompleta incorporación de las nuevas tecnologías de información y comunicación (TIC) en el ámbito familiar y educativo. En una segunda parte, se ha realizado una aplicación práctica tomando como referencia la gran obra universal “La Odisea”, cuya intención es mostrar la utilidad del videojuego como complemento educativo.

\section{Palabras clave}

Videojuegos, hábitos de juego, realidad virtual, sociabilidad, educación, herramienta educativa, TIC.

\begin{abstract}
The research is based on functions that videogames may do in education, a field that we considered unexplored mainly by three reasons: its recent incorporation, its educative unpopularity (the rejection like tool of learning and considered, on the contrary, like a distraction) and incomplete incorporation new technologies at home and educative field. In the second part, we have done a practical research taking as reference the great universal literature “The Odyssey”. The target is showing the videogames utility as educative tool.
\end{abstract}




\section{Key words}

Videogames - game habits - virtual reality - sociability - education - educative tools - new technologies.

\section{Introducción}

Katrin Baker narra una curiosa anécdota que le sucedió a una profesora canadiense que nosotros tomaremos prestada para iniciar nuestra introducción ${ }^{1}$ :

Leona Huggins sabía que algo no estaba haciendo bien cuando obligó a sus dos niños a interrumpir su partida (de videojuegos) para que se dedicaran a hacer sus deberes. Huggins: "Estaban inmersos en una tarea de compleja comprensión. Entonces me ví obligada a decirles: "Muy bien, se acabó la partida, tenemos que hacer vuestros deberes, hoy toca semántica. Tuve que interrumpir lo que yo considero una actividad de "alta concentración” por hacer unos deberes que sé que no lo eran”.

Leona Huggins, una profesora de primaria de Vancouver y madre de dos hijos de 6 y 11 años, respectivamente, es parte una nueva generación de padres y educadores que defienden la introducción de los videojuegos en las aulas.

La función educativa que pueden cumplir los videojuegos es, actualmente, un campo apenas explorado por tres motivos principalmente:

- Su reciente incorporación: estamos ante una industria que funciona, en el ámbito comercial, desde hace aproximadamente 30 años, y por tanto, existen pocos estudios al respecto.

- Su impopularidad educativa, promovida en gran parte por los medios de comunicación y la pedagogía.

- La incompleta incorporación de las nuevas tecnologías de información y comunicación (TIC) en el ámbito familiar y educativo.

\footnotetext{
${ }^{1}$ Games for Learning: Are schools ready for wht's to come?

http://www.gamesconference.org/digra2005/viewabstract.php?id=47
} 
Esta investigación pretende ser un acercamiento al uso educativo que permiten y desprenden los videojuegos. Hay pocas investigaciones realizadas, sin embargo, entre las pocas existentes, destacaremos aquellas que más repercusión han tenido en el ámbito educativo.

En una segunda parte aplicaremos la teoría a través de un videojuego en concreto: "La Odisea”, para el aprendizaje del mundo griego (mitología, cultura mediterránea y artes clásicas, entre otros valores).

\section{Situación de la utilización del videojuego en la enseñanza}

Por aprendizaje nosotros entendemos un cambio en la capacidad o disposición humana, que es relativamente duradero ${ }^{2}$. Con este objetivo, nace en el siglo XX, el nuevo concepto de “edutenimiento" 3 para referirse al aprendizaje adquirido a través de una determinada actividad lúdica, como son, por ejemplo, los videojuegos. Según De Kerckhove, “los videojuegos son un nuevo medio interactivo tan diferente como lo fue en su día la televisión para con la radio.

Representan nuevas formas de comunicación y abarcan un gran potencial de entretenimiento y educativo"4.

Edutainment es una extensión de las teorías que defienden que la actividad lúdica, además de entretener, potencia la maduración del ser humano pues afecta al cambio de comportamiento del saber, al intelecto, al desarrollo motor, a lo afectivo y a lo social ${ }^{5}$. En definitiva estaríamos, como hemos señalado en otros artículos, ante un homo ludens cibernético ${ }^{6}$ que adquiere estrategias fundamentales para el aprendizaje a través de los juegos virtuales: resolución de problemas, aprendizaje de soluciones, razonamiento deductivo y memorización. Además de experiencia en

\footnotetext{
${ }^{2}$ Definición extraída de la enciclopedia virtual http://es.wikipedia.org/wiki/Aprendizaje

${ }^{3}$ Edutainment es la unión entre “education” y “entertainment”, que significa “instruir jugando”. El término fue acuñado por Bob Heyman, documentalista de National Geographic. http://en.wikipedia.org/wiki/Edutainment

${ }^{4}$ De Kerckhove: "Video games are an interactive environment as different from television as television was from the radio. They represent a new means of communication and have a huge potential for entertainment and instruction”.

${ }^{5}$ Ver nota 3. http://en.wikipedia.org/wiki/Edutainment.

${ }^{6}$ Ciberjuego y sociabilidad:
}

Relaciones y efectos en los usuarios de juegos online (Word of Warcraft). Belén Mainer Blanco. http://www.ucm.es/info/especulo/numero31/ciberwow.html 
trabajo en grupo, de tipo cooperativo o colaborativo, y aprendizaje basado en las resoluciones de tareas $^{7}$.

Los videojuegos son la versión tecnológica moderna del juego tradicional y, para su explicación, nos serviremos de una de las teorías de aprendizaje más destacadas, la desarrollada por el psicólogo norteamericano Robert Gagné ${ }^{8}$. A grandes rasgos, este afamado investigador defiende que "el aprendizaje debe ser significativo para el alumno, va de lo general a lo especifico, cuenta con ciertas estructuras cognitivas organizadas jerárquicamente y se adquiere por descubrimiento en función de metas”.

Basándonos en su teoría y empleando como medio la plataforma digital, decimos que los usuarios adquieren cinco aprendizajes significativos mientras juegan con videojuegos:

- Destrezas motoras: ante un juego virtual los usuarios pueden probar y practicar nuevos movimientos de actuación que les dan uniformidad y regularidad en su manera de proceder derivada de su experiencia de juego.

- Información verbal: los juegos incluyen un amplio contenido verbal y escrito que el usuario tiene la obligación de comprender y asimilar para continuar la partida.

- Destrezas intelectuales: los jugadores aprenden a conectar la información dada y crean redes de significados.

- Actitudes: es muy usual que un jugador mantenga una ética moral de juego para con los demás jugadores.

- Estrategias cognoscitivas: potencian una mayor atención/concentración en la lectura y memorización del individuo.

Por tanto, señalamos que los videojuegos son transmisores de determinados valores que fomentan un cambio en la capacidad o disposición humana, relativamente duradero, que es el aprendizaje.

A partir de estudios realizados en 2005 por la investigadora Katrin Becker ${ }^{9}$, hemos desglosado los valores que se transmiten a través de los videojuegos ${ }^{10}$.

\footnotetext{
${ }^{7}$ McFarlane, 2002.

${ }^{8}$ Gagné, 1985. Gagné, Briggs and Wager, 1992. http://www.lsda.org.uk/files/PDF/1529.pdf

${ }^{9}$ Basados, a su vez en la teoría de Marc Prensky (2001).

${ }^{10}$ Los valores de Becker han sido traducidos y expuestos en negrita y su aplicación a los videojuegos se muestra a continuación de dichos apartados. Se pueden encontrar valores sociales adquiridos a través de los videojuegos en http://www.ucm.es/info/especulo/numero31/ciberwow.html
} 


\section{Atención constante del hilo narrativo (“atract mode”) mediante:}

- Información inicial: suele dar el contexto, los objetivos, metas y descripción del juego.

- “Clips o Miniescenas” audiovisuales, cuyo rol es fomentar la inmersión de los usuarios en

la historia que van a vivir como protagonistas y no como meros observadores (interactividad).

- "Recordatorios": los juegos ofrecen a lo largo de la partida información en forma de texto o escenas a la introducción del juego para no perder el hilo narrativo del juego que da globalidad y sentido a la obra. Estos contenidos suelen estar muy cuidados gráficamente, pues son vitales para la inmersión de los usuarios y, en muchos casos se presentan como recompensa, es decir, tras completar un objetivo/fase.

\section{Fuerza estimulativa:}

Recursos espectaculares que apelan a los sentidos de los jugadores, como son los elementos musicales, gráficos, sonoros, visuales... es decir, experiencias directas que adquieren los usuarios en la realidad a través del mundo virtual.

\section{Guía del aprendizaje:}

Los juegos enseñan a los usuarios cómo aprender a jugar, ya que cada videojuego y soporte ${ }^{11}$ tiene sus propias reglas y manejo. Los “tutoriales”"12 sirven para que los usuarios aprendan las normas y uso de los comandos mientras juegan, es decir, que facilitan mediante el atractivo de este tipo de ocio el aprendizaje del "manual” del juego.

También es común que las normas, especialmente el empleo de comandos, sean semejantes en todos los juegos, para crear un aprendizaje paralelo del usuario y facilitar su tarea de entretenimiento.

\section{Interactividad:}

Es esencial que el usuario sienta que forma parte de la historia y para ello ha de hallar respuestas en tiempo real en sus relaciones para con la máquina o para con los demás usuarios, en caso de

\footnotetext{
${ }^{11}$ Actualmente las dos plataformas que lideran el ocio digital son las videoconsolas y el PC. Sin embargo, se están realizando grandes inversiones en otras dos plataformas: el móvil e Internet.

12 Tutorial en videojuegos es una parte del programa donde se enseña al usuario sobre cómo jugar, generalmente sobre los mismos escenarios del propio videojuego.
} 
haberlos. Es la idea de “me habla a mí individualmente”. El jugador es el protagonista de la actividad que está ejecutando. Una forma positiva de estimular la interactividad es otorgando al individuo premios y elogios, que estimulan su auto-reconocimiento.

\section{Fomento del aprendizaje generalizado:}

Como hemos señalado en el apartado “guía de aprendizaje”, casi todos los videojuegos se ejecutan de forma parecida con ligeras variaciones, es parte del aprendizaje global y horizontal. Lo que se aprende en un juego se emplea en el resto y se fija en la memoria y hacer del usuario ya que se trata de aprendizaje por repetición ${ }^{13}$.

\section{Mundo de competitividad:}

Los videojuegos son un todo virtual en donde los usuarios se enfrentan a algún tipo de oposición, ya sea contra la máquina o contra otros jugadores. El vencimiento de los obstáculos proporciona eficacia, auto-superación y refuerzo en el juego. Es decir, el individuo adquiere confianza en su habilidad para desarrollar una acción y perseverar en ella.

\section{Instinto de descubrimiento:}

Los usuarios se deleitan con los hallazgos que van realizando de las zonas del juego y cómo van destapando las áreas del mapa, antes desconocidas. Es un reto indagar y vagar por el juego sin perseguir una meta más que la de recorrer el juego y descubrir cada rincón del mismo. El sujeto busca, prueba y explora diversos caminos con finales distintos, trucos e información privilegiada, en caso de haberla.

\section{Mundo de decisiones:}

El juego es una constante de toma de decisiones que afectan al resto de la partida. Por tanto, el usuario debe probar diferentes maneras de actuación hasta dar con la adecuada. La mayoría de las decisiones han de tomarse rápidamente, elevando así su margen de error y por ello, el usuario ha de ser veloz de pensamiento para tomar la decisión más adecuada o la que más le conviene en la partida porque, generalmente, no hay vuelta atrás. Esta característica, dota a los jugadores de independencia

\footnotetext{
13 “Atrapado en el tiempo”, dirigida por Harold Ramis. El protagonista principal se despierta cada mañana en su misma cama en el mismo día y hora. Sólo avanza la película cuando el personaje hace bien las cosas. Durante el film el protagonista va aprendiendo de sus errores. Hasta que finalmente es capaz de jugar bien su rol.
} 
en sus acciones y, por tanto, una mirada crítica ante lo que se enfrentan, ya que sus decisiones pueden determinar toda la partida.

\section{Mundo de jerarquía:}

Todos los videojuegos tienen normas y status sociales, lo que dota de cierta jerarquía al juego. En los juegos de rol, por ejemplo, los usuarios tienden a reunirse en grupos y a formar clanes, compuestos por miembros de diferente rango.

De manera gráfica, y para entender mejor los valores educativos que se pueden adquirir mediante los videojuegos, nos serviremos de la tabla que realizaron Attewell y Savill-Smith en 2003 a partir de investigaciones de Prensky sobre los usos educativos de los juegos:

\section{“Características de cómo los videojuegos contribuyen a la adquisición de aprendizaje de los} usuarios"

\begin{tabular}{|c|c|}
\hline Características del juego & Valores adquiridos \\
\hline Diversión & Satisfación \\
\hline Jugar & Inmersión \\
\hline Normas y reglas & Estructura \\
\hline Metas y objetivos & Motivación \\
\hline Interacción con el juego & Saber hacer \\
\hline Reciprocidad & Aprendizaje con respuesta inmediata \\
\hline Adaptación & Carácter abierto \\
\hline Ganar la partida & Aratificación del ego, auto-superación \\
\hline Competitividad, obstáculos & Fomento de la creatividad \\
\hline Resolver problemas & Aprendizaje social \\
\hline Interacción social & Emociones \\
\hline Narratividad & Adrenalina \\
\hline
\end{tabular}

(Attewell y Savill-Smith, 2003) 


\subsection{Valor de los videojuegos de simulación en la enseñanza.}

Los juegos de simulación ${ }^{14}$ son una nueva manera de entender el acto de jugar, puesto que no hay ni fichas, ni tablero, ni unas reglas estrictas (varios caminos posibles). Por el contrario, cada jugador interpreta un personaje ficticio, con una serie de características propias que le definen.

La clave de este tipo de ocio es, por tanto, la activa participación del usuario para con el juego ya que el individuo forma parte la vida digital.

Este tipo de juegos fomenta especialmente:

- La creatividad: el jugador elige el personaje que desea encarnar para luego actuar según la personalidad que le haya asignado. El individuo puede crear distintos personajes y jugar con ellos el mismo juego de diversa manera de actuación ${ }^{15}$.

- La participación: el usuario es el protagonista de la historia con inmediata interactividad.

- El gusto por la narratividad/literatura: los usuarios viven el antiquísimo arte de contar historias, es decir, conjugan narrativa y dramatización, ya que el jugador lee y protagoniza la historia a medida que la construye.

Existen varias teorías que defienden el empleo de los juegos de simulación para facilitar el desarrollo de la capacidad humana ${ }^{16}$. Según Leutner, en partidas de simulación multijugador ${ }^{17}$, los usuarios aprenden influenciados por factores sociales y culturales. Es decir, mediante la observación de otros usuarios se adquieren y asimilan aquellos resultados visibles de éxito y se identifican modelos que son imitados entre los usuarios.

\footnotetext{
14 El juego de rol (Role Playing Game) se desarrolló durante los años 1970 en Estados Unidos. Este tipo de ocio ha

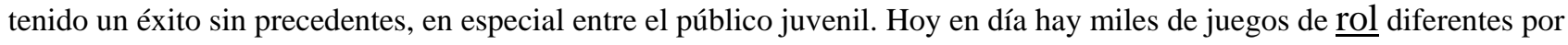
todo el mundo.

${ }^{15}$ El proyecto Becta aconseja que los usuarios creen varios personajes para aprender así la diversidad social y luchar contra el racismo. www.becta.org.uk

${ }^{16}$ Por ejemplo, el doctor Detlev Leutner ha señalado que los juegos de simulación son una buena herramienta educativa, ya que favorecen el aprendizaje por descubrimiento. “The use of computer and video games for learning”. http://www.lsda.org.uk/files/PDF/1529.pdf

${ }^{17}$ Opción de un videojuego que permite que varios usuarios puedan jugar juntos en una misma partida mediante la conexión entre máquinas. También algunas consolas, como la xBox, permiten esta opción dividiendo la pantalla en dos para que dos jugadores disfruten de una misma partida juntos.
} 
La ventaja de estos videojuegos reside en que el usuario se inserta en un escenario cualquiera y aprende de su entorno. Así, el juego puede emplear el recurso de la fantasía para generar en el usuario cierta curiosidad.

El investigador Kusunoki en el año 2000 enseñó con éxito a sus alumnos educación cívica y respeto al medioambiente a través de un juego de rol cuyo habitat era la naturaleza y la ciudad limpia. Los usuarios leían la información que les ofrecía el juego para luego aplicarla. Para avanzar, debían haber comprendido correctamente la información dada. Es decir, los juegos de simulación exigen la comprensión escrita/visual para poder avanzar en la partida.

Otra vez Leutner, a través del videojuego “Sahel Zone”, enseñó a sus alumnos el proceso del cambio climático y el valor de la ecología. En el juego, los alumnos encarnaban a un granjero con 10 áreas de tierra para cultivar. Todas las decisiones de los usuarios afectaban directamente al cambio climatológico y a la ecología y por tanto, el jugador, debía tener en cuenta estos factores a la hora de tomar sus decisiones.

Existen multitud de buenos ejemplos de juegos de rol: Desde los más recientes como el “Oblivion” hasta los más antiguos como el “Diablo”.

La clave reside en escoger el juego apropiado para un fin determinado. No debemos dejar en manos con fines comerciales la elección de los juegos didácticos para los menores. Determinados juegos facilitarán el aprendizaje de determinadas materias y no de otras, y viceversa. Algunos, servirán simplemente para el divertimento del usuario.

Esta clave podemos aplicarla a otros soportes lúdicos como la literatura o el cine. Determinados materiales pueden ser eficaces y otros simplemente no, por ello, la importancia del profesor o moderador que guíe a los usuarios en la elección de los videojuegos que se empleen para el aprendizaje.

\subsection{Ser conscientes y responsables con el uso de los videojuegos en el aprendizaje}

Este estudio encuentra efectos positivos y negativos en el empleo de los videojuegos en la educación.

Los positivos ya han sido citados con detalle en la parte primera del artículo, accederemos a los dos principales efectos negativos que pueden derivar de un mal uso de los videojuegos en el ámbito del aprendizaje y que, por tanto, deben ser vigilados y evitados: 
- El uso ilimitado y no vigilado: para ejercer un mayor control sobre los contenidos que consumen los menores, la industria del software interactivo se ha comprometido a informar al público general mediante la clasificación PEGI, apoyado por la mayoría de los países comunitarios. Esta clasificación informa de las edades recomendadas y del tipo de contenidos de los productos. Además, existen campañas de concienciación donde se ofrece información sobre videojuegos, consejos y consultas a expertos, entre otros servicios, para que conozcan el medio de comunicación social en el que se mueven sus hijos ${ }^{18}$.

- La disposición favorable al juego y no a otros quehaceres que exigen responsabilidad y esfuerzo por parte del individuo. Los usuarios de videojuegos mantienen, generalmente, una "actitud", "interés" y "valor" positivos hacia el propio juego, sin embargo, algunos investigadores han criticado que este tipo de actividad lúdica sólo fomenta el aprendizaje divertido, dejando a un lado la responsabilidad de aprender otros contenidos menos divertidos, pero sí necesarios ${ }^{19}$.

El objetivo es, como apuntó el antropólogo americano David Stoll ${ }^{20}$, que el videojuego sea objeto de iluminación/aclaración y no de sólo entretenimiento.

Stoll: “Aprender cómo adquirir la información, maximizar la eficacia a través de la diversión. Es decir, desarrollar la capacidad humana, lo que no significa que haya que denigrar las dos tareas que nos hacen madurar como humanos: aprender y enseñar”.

Por esta razón es importante perfilar y resaltar la actividad del profesor o moderador para que sea un guía a través de este tipo de ocio y no un mero espectador. La esencia de un videojuego es el entretenimiento, pero esa diversión puede ofrecer múltiples posibilidades de aprendizaje. Para ello, el profesor debe conocer el medio para ser capaz de tomar las herramientas más adecuadas para el aprendizaje de los contenidos educativos.

La tarea del educador debe estar perfectamente planificada, por tanto, comprenderá desde la anticipación de conocimientos del sujeto, su formulación de objetivos, activación de conocimientos

\footnotetext{
${ }^{18}$ A través de Internet se pueden encontrar prácticas guías como "Aprende y juega con EA" (Electronic Arts) o "la Guía de Videojuegos para Padres, una iniciativa del Defensor del Menor de la Comunidad de Madrid.

${ }^{19}$ Varios investigadores defienden esta posición como Dempsey en 1996.

${ }^{20}$ David Stoll, High Tech heretic-reflexions of a computer contrarian, 1999.
} 
previos para construir nuevos aprendizajes sobre ellos y potenciar la capacidad de relacionar los contenidos para un entendimiento eficaz.

Es decir, será de vital importancia adaptar los nuevos contenidos al nivel del alumno, para que éste pueda fácilmente asimilarlos. La idea es formar jugadores competentes, que entiendan el objetivo de la enseñanza.

César Coll (1993) dijo: “Comprender significa establecer un sentido para una nueva experiencia retrocediendo a elementos parecidos de experiencias ya asimiladas” ${ }^{21}$.

A través del material dado, el sujeto tiene la labor de interpretar y relacionar contenidos, puesto que "el objeto interpretado no se impone jamás, si no que no que será siempre una

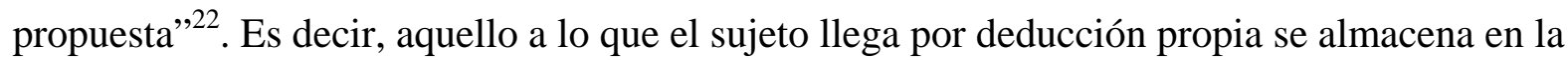
memoria y es reforzamiento de la actividad intelectual del individuo.

Y este pensamiento nos lleva a lo expuesto en un principio: el profesor ha de ser guía y acompañante del alumno y para ello debe estar preparado y formado en las nuevas tecnologías, y más concretamente en los videojuegos que hoy son un entretenimiento mayoritario de las nuevas generaciones.

\section{Literatura y videojuegos: diferencias de enfoque, "La Odisea" y otros ejemplos}

Una niña llega a su casa y le dice a su madre que la profesora le ha mandado a su clase leer la segunda parte de “El Quijote”.

-¿Pero te has leído la primera parte de “El Quijote”?, pregunta la madre confusa.

- “No”, contesta la niña.

- “No entiendo nada, hija. ¿Por qué te mandan la segunda parte sin haber leído la primera?

- “iMamá! Cada año la profesora manda una parte distinta para que los alumnos no se pasen los apuntes de año en año y a nosotros nos ha tocado la segunda parte...”.

\footnotetext{
${ }^{21}$ Isabella Leibrant. "Las herramientas electrónicas en la didáctica de la literatura”. Tesis doctoral inédita por la Universidad de Navarra, 2006.

${ }^{22}$ Cit de Parelson. Ver nota 21.
} 
Seguramente la niña acuda a la World Wide Web, entre en el Rincón del Vago, “fusile” un resumen de la segunda parte de “El Quijote” y jamás vuelva a intentar abrir una de las obras más emblemáticas de la Literatura Universal y la abanderada de la Literatura Española ${ }^{23}$.

Este ejemplo, lamentablemente, se está reproduciendo en muchos colegios españoles y no es un caso aislado de la educación que reciben nuestros menores. Para que esto no suceda, los guías (padres, profesores y la sociedad en general) deben buscar la forma más provechosa para el aprendizaje del alumno. El objetivo será enseñar contenidos de calidad a los niños sin “matar” los propios contenidos.

La obra de la que nos hemos servido en este artículo es la gran epopeya “La Odisea”, de Homero, reconocida por muchos como la primera gran aventura de la historia. La Odisea posee un esquema narrativo que ha sido repetido a lo largo de la historia en multitud de obras ${ }^{24}$. Es uno de los grandes clásicos de la literatura Universal e imprescindible para el entendimiento del Mundo Clásico.

“La Odisea” se ha interpretado para niños en diferentes formatos. En literatura, se han realizado adaptaciones infantiles y juveniles de la obra de Homero, como la de la editorial Espasa juvenil. Además, a través de Internet se pueden encontrar multitud de páginas con consejos para su aprendizaje, lectura y disfrute ${ }^{25}$ enfocados a públicos diferentes.

En cine, Andrei Konchalovsky no dudó en llevar la historia del héroe a la gran pantalla con un reparto protagonizado por Armand Assante e Isabella Rosellini en 1997 con el título de “The Odyssey”.

En teatro ha sido llevada en multitud de ocasiones, como es el caso del escritor Mario Vargas Llosa y la actriz Aitana Sánchez Gijón, quienes encarnarán a Ulises y a su esposa Penélope en el $52^{\circ}$ Festival de Teatro Clásico de Mérida que se celebrará este verano ${ }^{26}$.

En televisión, existe una original serie de dibujos animados llamada “Ulises 31 ” que recientemente ha sido difundida por canal de televisión “Cuatro”. Esta serie respeta la carga mitológica griega, pero también añade elementos inventados y fantásticos del gusto de los críos. Por

\footnotetext{
${ }^{23}$ Anécdota de una profesora de literatura titular universitaria en el CAP (Certificado de Aptitud Pedagógica).

${ }^{24}$ La historia del clásico héroe que debe superar pruebas y sufrimientos para llegar a casa.

${ }^{25}$ Ejemplos de webs:

http://alerce.cnice.mecd.es/ mcui0001/indice.html;

http://www.elhuevodechocolate.com/odisea1.htm;

http://adigital.pntic.mec.es/ aramo/lectura/lectu52b.htm

26 “Odiseo y Penélope”. www.festivaldemerida.es
} 
ejemplo, la escena se sitúa en el espacio. La nave de Ulises no es un barco, sino una estación espacial y sus aventuras tienen lugar en diferentes planetas.

La pregunta que todo tutor debería hacerse es: ¿sería adecuado para su aprendizaje el empleo de los videojuegos?

Sabemos que este tipo de entretenimiento capta la atención de los alumnos mediante estrategias y recursos llamativos, no en vano supone un 35\% sobre el total del ocio audiovisual e interactivo en España y ha recaudado 863 millones de euros en $2005^{27}$. Por tanto, podemos afirmar que esta herramienta es del gusto de los niños y se sentirán, por tanto, atraídos por su carácter interactivo y de implicación directa con el medio.

Sin embargo, y como hemos citado anteriormente, la diversión que este tipo de ocio suscita en los menores no debe restar importancia a la propia enseñanza ${ }^{28}$. El videojuego debe servir de herramienta para la compresión de "La Odisea" sin sustituir a la misma obra ${ }^{29}$.

Una vez considerado el videojuego como una herramienta eficaz, el paso posterior sería: ¿qué saben los alumnos sobre “La Odisea”, cuáles son sus ideas previas a la lectura? Investigar sobre lo que saben es la base del nuevo aprendizaje. Según Schutte ${ }^{30}$, habrá que realizar una primera descripción del texto como punto de partida, lo que sería la primera aproximación del texto y determinar lo que se espera de la obra.

Una primera descripción es:

El videojuego de “La Odisea, la búsqueda de Ulises” trata de ir al rescate del protagonista y pasar todas las pruebas que el héroe sufrió. El hábitat es la época de Troya. Penélope espera el regreso de su esposo Ulises desde hace nueve años, asediada por perversos pretendientes. Mientras, su hijo Telémaco ha partido en busca de su padre. El jugador asume el papel del soldado Eriseo, que estuvo a las órdenes de Ulises en la guerra. Eriseo es llamado por Penélope, quien le ordena traer a casa a su esposo lo antes posible. Para ello, deberá recorrer todas las aventuras que sufrió el héroe ${ }^{31}$.

\footnotetext{
${ }^{27}$ Datos obtenidos de los informes anuales de la Asociación Española de Software de Entretenimiento (Adese).

${ }^{28}$ David Stoll, High Tech heretic-reflexions of a computer contrarian, 1999.

${ }^{29}$ Consideramos este medio también un recurso conceptual, pues, como se cita en la primera parte de este artículo, a través del juego se adquieren también valores de comportamiento.

${ }^{30}$ Isabella Leibrant. “Las herramientas electrónicas en la didáctica de la literatura”. Tesis doctoral inédita por la Universidad de Navarra, 2006.
}

${ }^{31}$ El juego ha contado con la participación de académicos y expertos en arqueología del Mundo Clásico. 
A partir de este momento, el profesor debe a través del juego, que es sumamente interactivo y participativo, planificar y analizar los objetivos. Podemos decir que la enseñanza de la literatura se reduce principalmente a tres objetivos fundamentales ${ }^{32}$ :

1. Placer estético/actitudes emocionales: Disfrutar la considerada primera gran aventura de la historia.

2. Conocimiento de las manifestaciones culturales y sociales.

Peculiaridades del Mundo Clásico: introducción general a la época históricamente.

Conocer la cultura, tradición y mitología de la Grecia clásica y, por extensión, la cultura mediterránea a la que España pertenece.

Interpretar los contenidos: Blanco Sarto (1998), dijo: “La interpretación es un acto personal sin que eso sea un obstáculo sino una vía de acceso al conocimiento de la obra. Es decir, hacer de la enseñanza una llamada, una propuesta que se ofrece a la interpretación. Es comunicación.

Desarrollar la capacidad de transferir los conocimientos asimilados a otras áreas. Fomentar con los alumnos actitudes interactivas y participativas.

3. Manifestaciones literarias como comunicación y ejemplo del uso correcto de la lengua. Conocer a Homero, quien para Hegel fue "el elemento en el que el mundo griego vive como el hombre vive en el aire"33.

Introducción general de los rasgos literarios de la época: obras y autores destacados del momento. (“La Ilíada”, de Homero; “Las Metamorfosis”, de Ovidio”, por ejemplo).

Conocer las características del género épico y la poesía oral: análisis morfológico, sintáctico y semántico del texto.

${ }^{32}$ Didáctica de Lengua y Literatura. Formación de profesores en la educación secundaria. pg 137.

${ }^{33}$ A Homero se atribuyen las composiciones de la Ilíada y la Odisea. Aunque hay dos grandes teorías sobre su autoría:

- "La Odisea” es fruto del ensamblaje de varias obras de distinta procedencia, lo que explicaría las numerosas incongruencias que contienen. Esta teoría es la más aceptada. Entre sus seguidores están filólogos como Friedrich August Wolf.

- Milman Parry, en 1934, grabó una serie de poemas de bardos yugoslavos que no sabían leer ni escribir. Su recitado duraba varias semanas y comprobó que no era una interpretación al azar, se necesitaba poseer una técnica rigurosa para recitar versos que fueran equilibrados y usar fórmulas estereotipadas como las que aparecen en lo poemas de Homero. Por tanto, sus composiciones son únicas, según Parry, ya que hacia el año 750 a.C., cuando las obras fueron escritas la literatura se transmitía en forma oral, sin apoyo de la escritura. 
Analizar cómo una misma obra ha sido expresada a través de distintos medios: cine, teatro, videojuegos.

Aprender mediante la lectura el correcto empleo del castellano escrito (lenguaje culto). Propuestas temáticas/iconográficas para el estudio de “La Odisea” en las aulas.

Conocer los mitos y símbolos del Mundo clásico es comprender el significado de gran parte de la cultura española. Mediante el videojuego, “La Odisea, la búsqueda de Ulises”, el alumno tendrá la oportunidad de asumir el papel del soldado griego Eriseo, es decir, podrá vivir como lo hicieron entonces nuestros antepasados y aprender su cultura clásica.

A continuación, hemos realizado una agrupación temática sobre las tareas que el alumno podría realizar en el aula para el aprendizaje del Mundo Clásico a partir la lectura de la obra de “La Odisea” y del videojuego.

\section{LA MITOLOGÍA/LA RELIGIÓN}

La mitología griega es un conjunto de mitos o creencias religiosas que explican historias y leyendas sobre una gran variedad de dioses. Estas historias suelen ser de carácter explicativo, ya que, por ejemplo, esclarecen el origen del mundo y su funcionamiento.

Estas historias y leyendas fueron adoptadas por el imperio romano, han sido reproducidas a lo largo de la historia y hoy permanecen en la cultura mediterránea. Será pues de un valor indiscutible su aprendizaje (conocimiento de las diferentes deidades y lo que representan, su organización y sus vidas relacionadas).

La mitología griega se desarrolló plenamente alrededor del año 700 a.C, época aproximada de la creación de “La Odisea”. En la obra de Homero, aparecen multitud de deidades, aunque cobran especial relevancia:

- Zeus: dios de mayor rango y el más poderoso, soberano de todos los dioses del monte Olimpo.

- Poseidón: siguiente en rango a Zeus. Dios del mar.

- Atenea: hija favorita de Zeus. Diosa de la sabiduría, las artes, la belleza interior, la educación y la guerra.

- Hermes: mensajero del Olimpo. Dios de la orientación, los viajeros, los pastores, el consuelo y las reuniones.

En el videojuego, el jugador será presentado ante los dioses, quienes entablarán conversaciones con el usuario y le designarán misiones. Atenea, por ejemplo nos regalará un escudo, elemento 
significativo, si comprendemos que su padre Zeus le regaló su vez uno a la diosa. Otra importante deidad será la presentada en la batalla final. El jugador deberá enfrentarse contra el dios Poseidón, quien está enojado porque Ulises dejó ciego a su hijo Cíclope. También, los alumnos pueden buscar iconografía de los dioses del Olimpo, como por ejemplo:

\section{ATENEA}

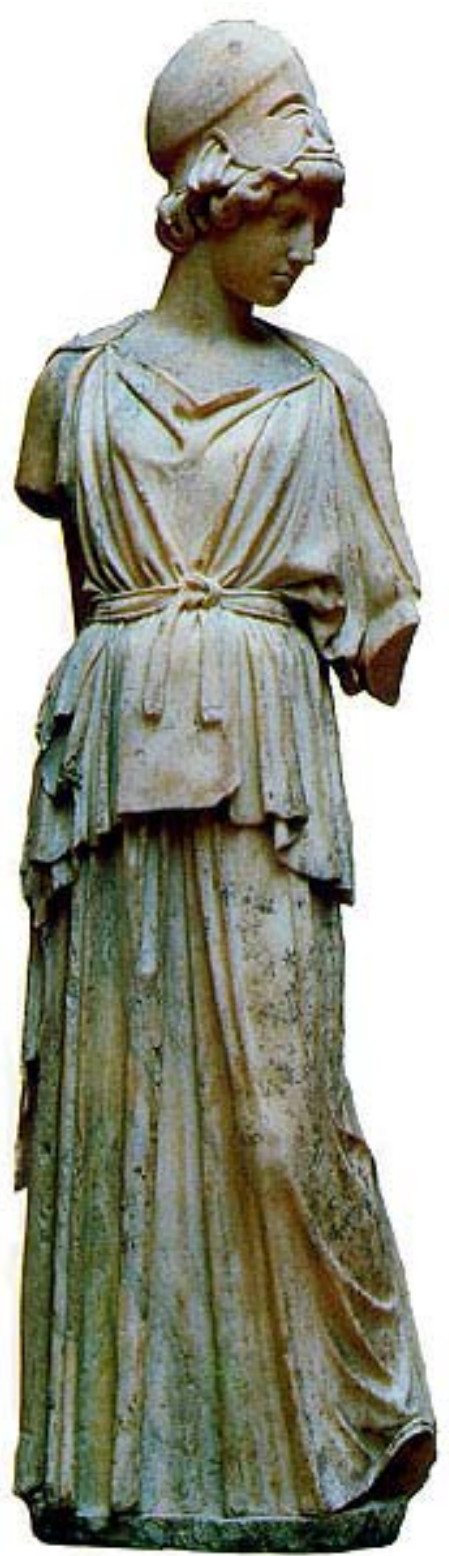

\section{POSEIDÓN}

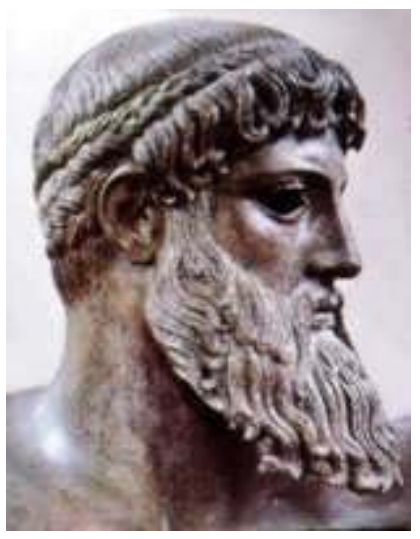

\section{HERMES}

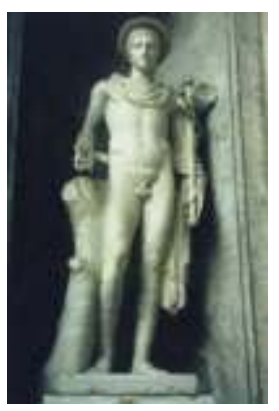

ZEUS

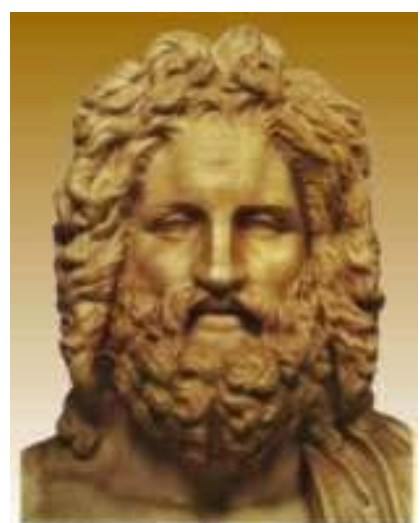


Y también podrán probar su aprendizaje como ejercicios como una sopa de letras:

\section{SOPA MITOLÓ}

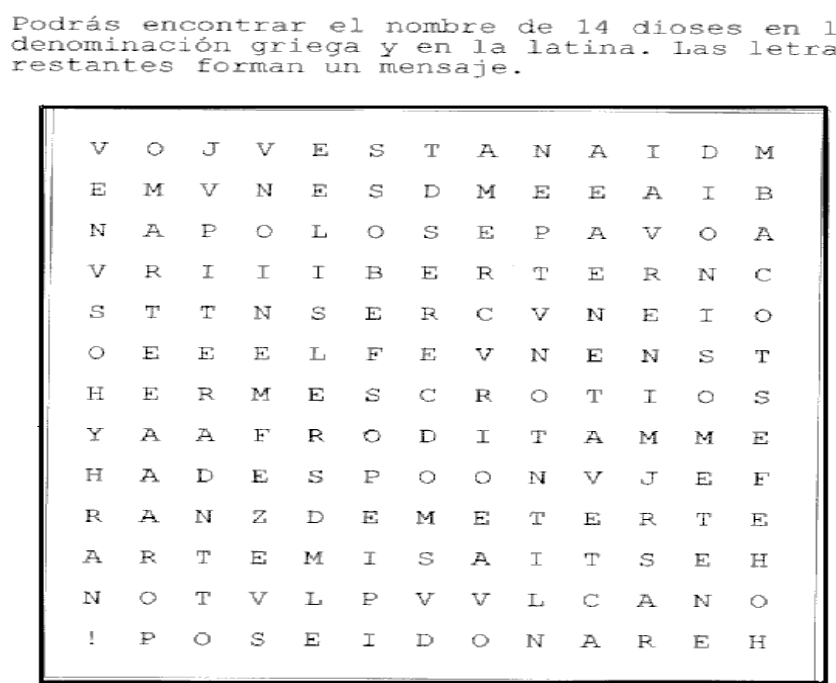

LADA OVEJA KON SU PAREJA

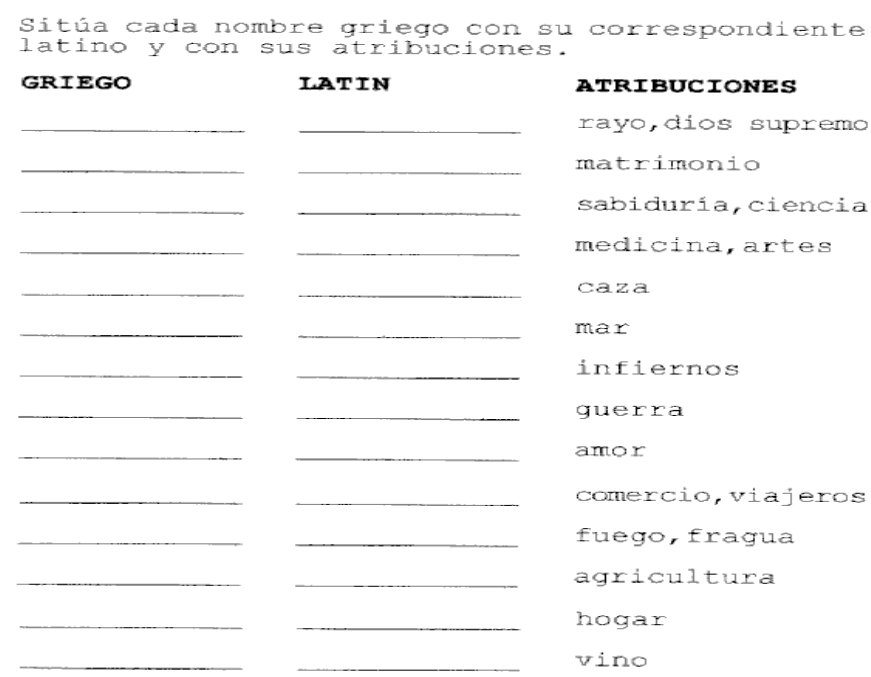

\section{ORGANIZACIÓN DE LA SOCIEDAD Y LAS CIUDADES}

La poesía homérica está referida al periodo micénico ${ }^{34}$, donde hay una civilización Palacial cuya cabeza es el Rey, rodeado de una Nobleza nombrada por él con carácter reversible y un complejo aparato burocrático ${ }^{35}$. En “La Odisea”, se precia una detallada descripción de este tipo de organización cuando Ulises llega al reino del soberano Menelao.

\footnotetext{
34 “La Ilíada y la Odisea: temática. El héroe homérico”. http://www.culturaclasica.com/literatura/grecia/epica2.htm

${ }^{35}$ Existe un paralelismo entre esta organización con la de la mitología griega, cuyo rey es el dios Zeus.
} 
La familia del mundo micénico se centra entorno al cultivo familiar, donde el campesino es libre. Del cultivo familiar se producen los alimentos y los hilos para la actividad de tejer de la mujer griega $^{36}$.

Penélope, la mujer de Ulises, es famosa por su don con el telar ${ }^{37}$ y por personificar el ideal de la esposa griega: casta, obediente y capaz de administrar los bienes de su casa. En el videojuego, el jugador tendrá la oportunidad de ser recibido por la misma Penélope, quien le ordena ir en busca de su marido, largo tiempo desaparecido.

En cuanto a la ciudad griega, el jugador, podrá visitar las zonas públicas (templos, el ágora y mercado) y las casas privadas. Además, de los palacios, típicos de la época micénica como el de Ulises.

Un práctico ejercicio, será en de diseñar una polis, una casa y un palacio griego. Además, podrá dibujar la organización de sus ciudadanos y familias. Algún ejemplo de construcción micénica sería:

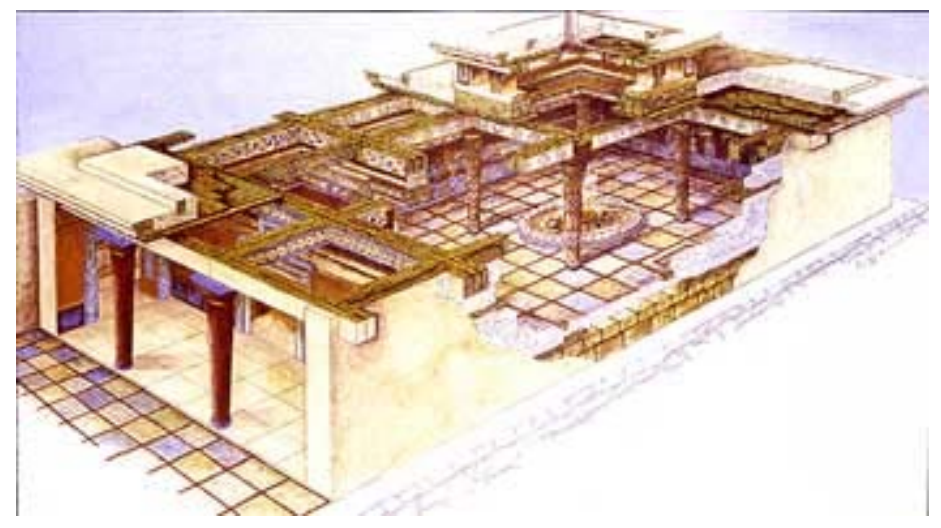

\section{Reconstrucción de un palacio micénico ${ }^{38}$}

\section{GEOGRAFÍA: confección de un mapa geográfico}

El héroe Ulises recorrió un largo camino antes poder regresar a su hogar. Estas aventuras serán vividas por el alumno a través del videojuego y, por tanto, sería muy interesante que realizara un

\footnotetext{
${ }^{36}$ Las familias nobles poseen esclavos que les cuidan sus tierras.

${ }^{37}$ Penélope teje durante el día y desteje durante la noche su telar para despistar a sus pretendientes y dar más tiempo a su marido para que regrese.

${ }^{38}$ Estructuras palaciegas micénicas. http://www.dearqueologia.com
} 
mapa por las zonas por las que ha viajado. Es decir, en esta investigación se propone la confección del mapa de los viajes de Ulises como el que se muestra a continuación ${ }^{39}$ :

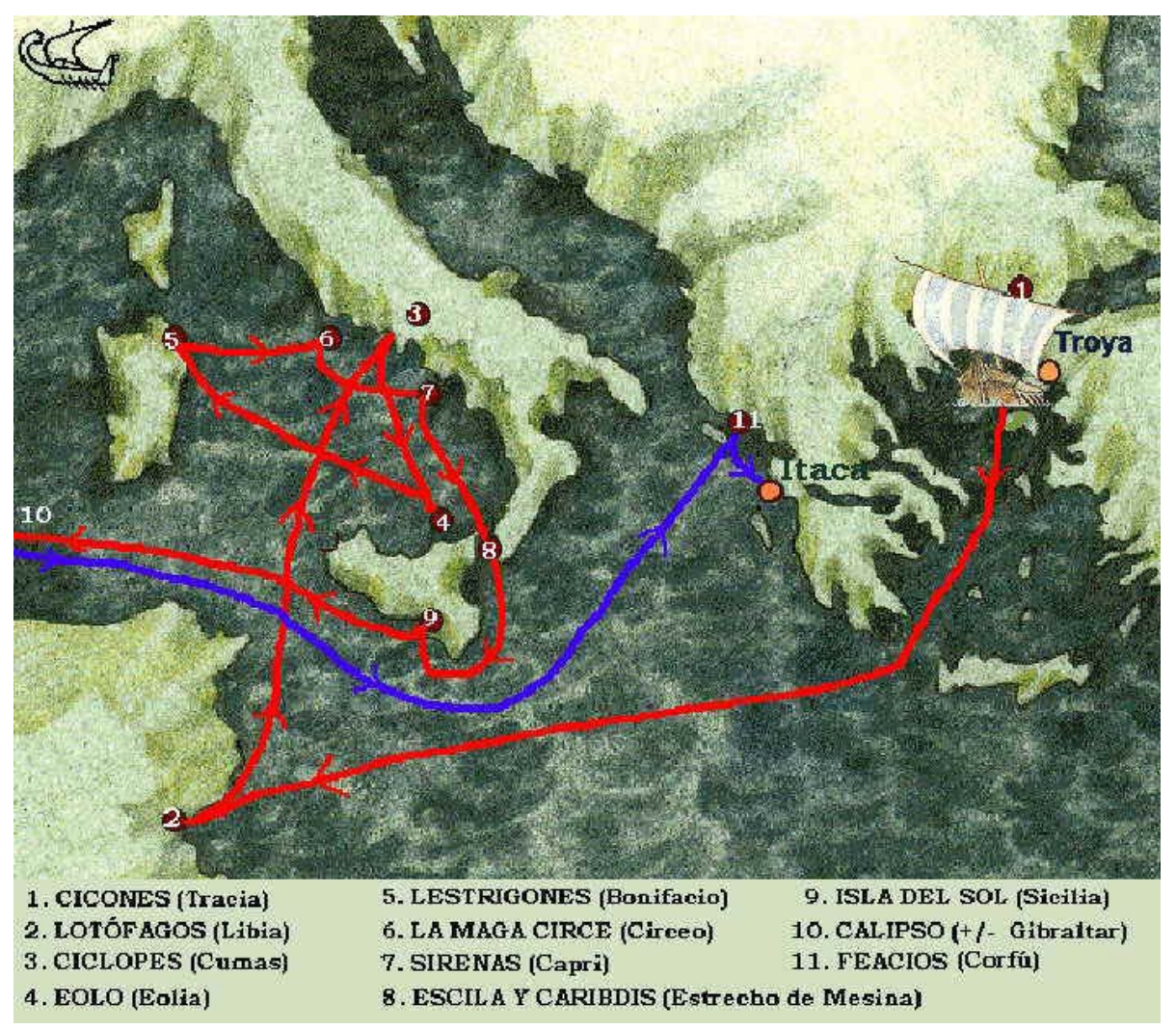

Además, se podría realizar un mapa sobre la concepción que los griegos tenían sobre La Tierra. A continuación, hemos presentado un mapa sobre cómo percibía Homero el planeta ${ }^{40}$.

\footnotetext{
${ }^{39}$ Mapa obtenido en la web http://www.culturaclasica.com/cultura/viajes ulises.htm

${ }^{40}$ Mapa extraído en la web http://www.culturaclasica.com/cultura/viajes ulises.htm
} 


\section{EL MUNDO MITTKOO DE HOMERO}

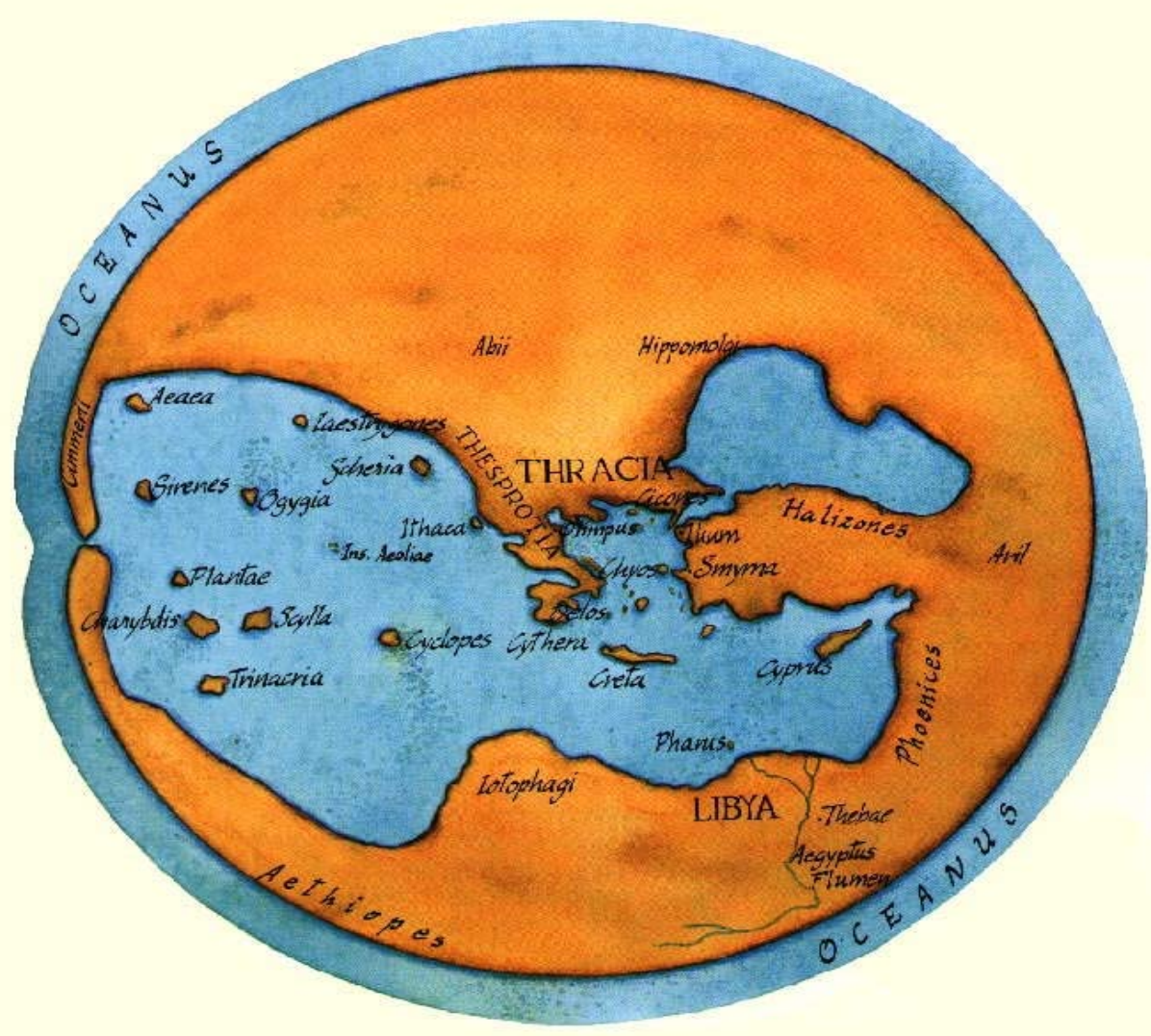

EL MLNDO MITICO DE HOMERO (Hacia 700 a.C.)

Conocer un territorio es dibujarlo, representarlo, traducirio a unas coordenadas precisas. Conocer el mundo es definir sus límites. En la representación cartográfica se aúna el trazado escueto de caminos, ríos y ciudades, con la visión ideológica y la concepción del universo.

Fn la Antigüedad, en la narración de Homero (700 a.C.), el Ocćano marca los limites de las tierras conocidas, concebidas como un disco circular con Grecia en su centro, y es también el mar el que desdibuja los contornos de los reinos y ciudades míticas. Pero los caminos del mar están abiertos, y fenicios y griegos transforman la vaguedad y la brama de los primeros mapas en puertos florecientes, dirsenas bañadas por e. sol y ciudades a la medida del hombre. Andalucía representaba el extremo occidente cel mundo conocido, paraje mitico para las aventuras de Hércules.

\section{EL CULTO A LOS MUERTOS Y LA VIDA DE ULTRATUMBA}

En la "La Odisea", la muerte es un tema siempre recurrente. Para los griegos era un deber ineludible enterrar a los muertos, ya que las almas de los que no recibían sepultura ni rito funerario estaban condenadas a vagar eternamente y a perseguir a sus parientes por haber descuidado el cumplimiento de los preceptos religiosos con los difuntos. 
En la obra Ulises viaja al Hades (infierno), situado bajo tierra. Allí se encuentra el barquero Caronte. El jugador en el videojuego seguirá los pasos del héroe y pedirá al barquero viajar al otro lado río Estigio.

Luciano de Samosata describió el Hades de la siguiente forma ${ }^{41}$ :

"...creen que bajo tierra hay un lugar profundo, grande, amplio, oscurísimo y sin sol. Es el Hades. En aquel abismo enorme reina el hermano de Zeus, llamado Plutón. En primer lugar se encuentra la laguna Aquerusia. Nadie la puede cruzar ni vadear sin un barquero, ya que su profundidad no permite traspasarla a pie y su anchura es excesiva para atravesarla a nado y, en fin, ni siquiera las aves muertas pueden alcanzar la otra orilla volando. Inmediatamente junto a la bajada y a la puerta, que es de acero, Éaco se encarga de custodiar la entrada sin pausa. A su lado Cérbero, el can de tres cabezas, bravísimo, muestra su cara amical y pacífica a los que llegan, pero atemoriza a los que intentan huir con sus ladridos incensantes y sus afilados colmillos.

Allí imperan Plutón y Perséfone, y tienen poder sobre todas las cosas. Dos son los que están sentados como magistrados, gobernadores o jueces. Los humanos buenos, justos y que llevaron una vida virtuosa, en cuanto se reúnen en grupos, los mandan a los Campos Elíseos para que lleven allí una vida felicísima. En cambio, cuando llegan a sus manos los malvados los envían al lugar destinado a los impíos, para que reciban el castigo que les corresponde por sus culpas e injusticias.

Los hombres de vida mediocre, que son la mayoría, andan errantes por el prado, sin cuerpo, todos convertidos en sombras que con el tacto se desvanecen como el humo. Se nutren de las ofrendas y las libaciones que les hacemos en sus sepulcros. De manera que si alguno acá, en la tierra, no dejó ni parientes ni amigos, aun muerto, padece hambre y vive entre los muertos atormentado por falta de alimento”.

El capítulo de "Descensus ad Inferos” de la obra de “La Odisea” y la Misión 4 en el videojuego están dedicados al Hades. Estos pasajes insertan al lector/jugador en la creencia griega del más allá y el respeto que se tenía a la muerte.

En el videojuego, el soldado Eriseo, es decir, el jugador, correrá la suerte que se creía tenían los griegos al fallecer. Cruzará el río, sobornará al guardián, esquivará al terrible perro de las tres

\footnotetext{
${ }^{41}$ Luciano de Samosata (Samosata, 125 - ¿181? d. C.), fue un escritor sirio. En su obra "Sobre el luto” redactó esta visión del Hades. Este fragmento ha sido recogido de http://www.culturaclasica.com/cultura/vida_ultratumba.htm
} 
cabezas, será juzgado en la “Cámara de los Jueces” y según sus acciones y decisiones tomará caminos distintos. Visitaremos los tres destinos posibles: donde vagan las almas mediocres, los Campos Elíseos (donde están los humanos virtuosos) y los Campos Asfódelos (donde residen los impíos).

\section{MODA}

Los alumnos también pueden aprender sobre la vestimenta del Mundo clásico. En "La Odisea”, Ulises es vestido con los mejores ropajes en los palacios a los que va llegando en su interminable viaje. En el videojuego, el soldado Eriseo vestirá como un auténtico griego y tendrá la oportunidad de ver en primera persona los ropajes de los demás ciudadanos, esclavos y dioses.

Los alumnos podrán buscar, además, iconografía del vestuario de entonces. Este ejercicio puede ser de gran atractivo para las alumnas. La mujer griega, noble y libre, dedicaba gran parte de su tiempo al acicalamiento personal ${ }^{42}$. Así lo han demostrado valiosos objetos de tocador, la riqueza de su vestimenta y sus joyas, entre otros objetos que han llegado hasta nuestros días.Un ejemplo iconográfico es el realizado por Thomas Hope bajo el título de "Vestuario de mujeres griegas”“3.

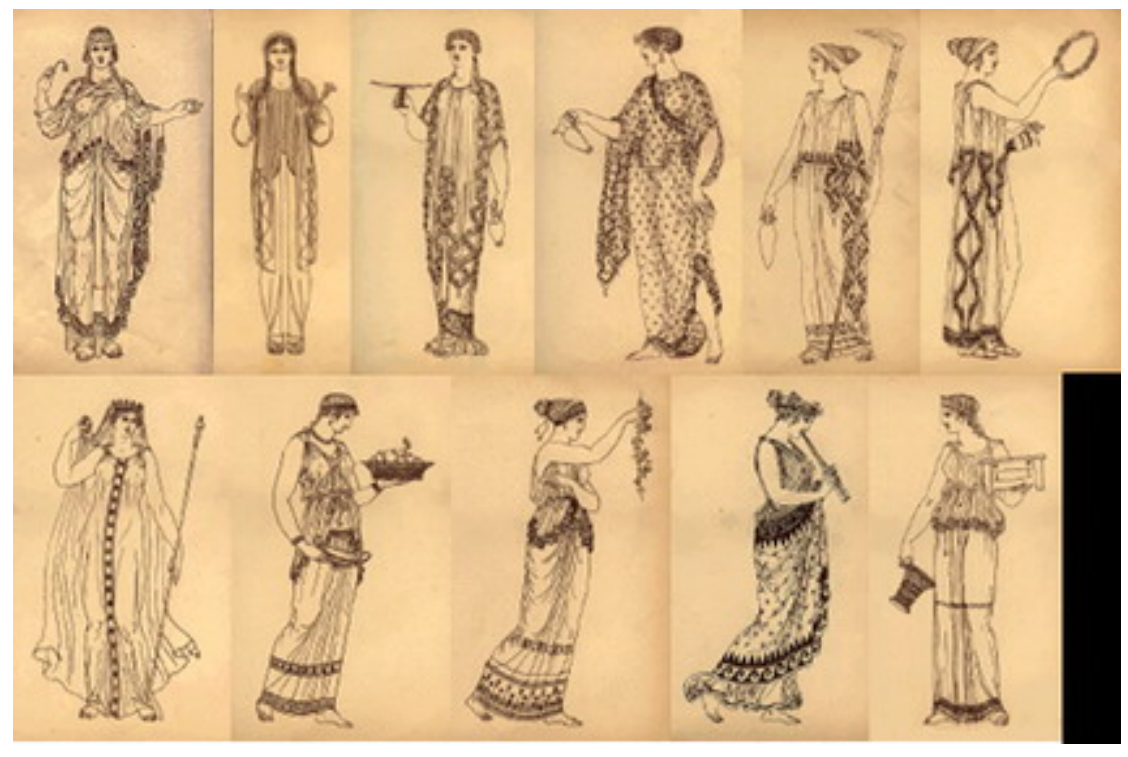

\footnotetext{
42 “La mujer a través de la iconografía doméstica”, Pilar González Serrano. http://www.ucm.es/info/seic/online/mujer.htm

${ }^{43}$ Fuente: "Costumes of the greeks and romans", Thomas Hope. Dover Publications,Inc. New York
} 

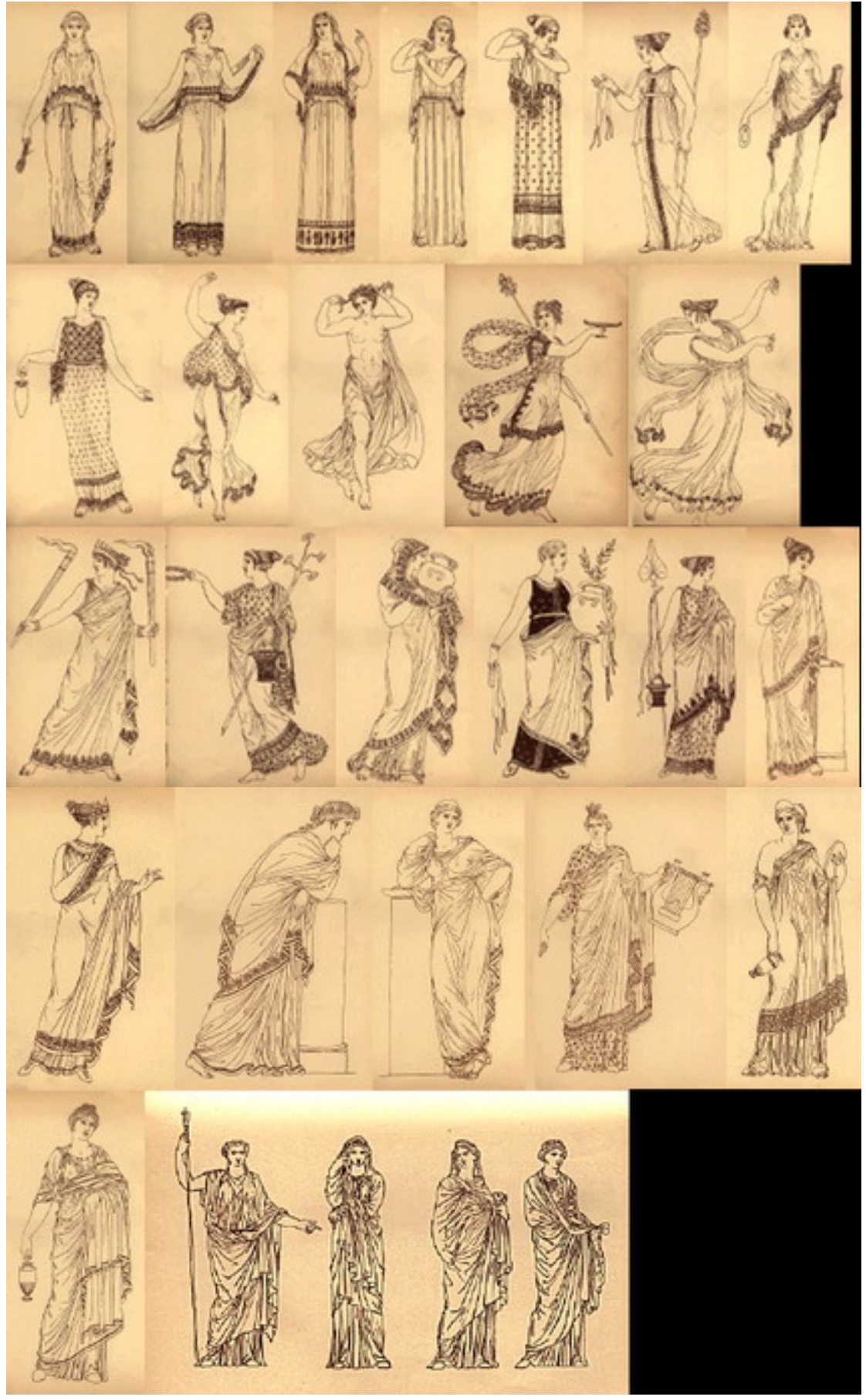

"Costumes of the greeks and romans", Thomas Hope. Dover Publications, Inc. New York.

\section{COMIDA COMO UN ACTO SOCIAL}

Reunirse para comer es un acto social dentro de la cultura mediterránea. En "La Odisea” es de vital importancia. Ulises es convidado, primeramente, a participar de un gran banquete en cada palacio al que llega en su tormentoso viaje. Mientras, los pretendientes ultrajan las posesiones del héroe de una 
manera horrible, consumiendo toda su hacienda en banquetes. También se realizan banquetes de sacrificio a los dioses, y se invita a todo forastero a participar de los convites.

“El vino” es imprescindible en los banquetes y es necesario para festejar cualquier acontecimiento. Dicen en “La Odisea”: "Y los jóvenes coronaron de vino las cráteras”. Y es que los viñedos son riqueza en Ítaca, tierra de Ulises. En el videojuego, se explica la importancia del vino en la cultura griega mediante una prueba en la que se debe obtener un determinado vino de una determinada viña. En la misión se recorren viñedos y se entra en contacto con la gran actividad económica agrícola griega.

\section{NARRATIVA: confección de un cuento epopéyico}

Una buena actividad para desarrollar la creatividad literaria de los alumnos sería escribir una historia de género épico, donde un héroe deba superar terribles obstáculos para alcanzar su meta. Podría ser una actividad de creación colectiva o individual.

\subsection{Aprendizaje: Un cambio relativamente duradero}

Si los objetivos establecidos para "La Odisea” se "han sabido hacer”, el alumno debe ser capaz de interrelacionar los contenidos y estrategias educativas a otras áreas.

El éxito del aprendizaje consistiría en, por ejemplo, transferir lo asimilado a la época del Renacimiento mediante el recién estrenado videojuego de “DA VINCI Experience”, que recrea la vida y obra del genio Leonardo da Vinci, donde el usuario tiene la oportunidad de lidiar con los misterios de los códigos escondidos en la obra del gran genio italiano y vivir en el corazón una época de esplendor italiano.

Existen multitud de buenos videojuegos de los que se puede extraer contenidos educativos, como se ha realizado con "La Odisea”. Por ejemplo, el alumno debe poder aprender sobre Julio Verne y sus “20.000 Leguas de Viaje Submarino”, a través de la aventura gráfica “El Secreto de Nautilus”, donde un científico experto en arqueología submarina viaja en el submarino USS Shark rastreando los fondos marinos.

Otros juegos lúdicos serían “Atlantis”, “Aztecas” o “China”, útiles herramientas para el aprendizaje de diversas áreas educativas. El esquema propuesto de “La Odisea” pretende ser un aprendizaje que pueda ser transferido a otras enseñanzas de forma práctica y divertida. 


\section{Conclusiones}

Muchos docentes $^{44}$ se han comprometido con la tarea de incorporar las nuevas tecnologías de la información y comunicación (TIC) en el aula con la convicción de que facilitan el arte de enseñar y aprender. Este artículo se adscribe dentro de esta idea, especialmente en el rol que los videojuegos pueden desempeñar en el aprendizaje de los alumnos.

Sin embargo, esta idea cuenta con tres grandes contrapartidas: su reciente incorporación, su impopularidad educativa y la incompleta incorporación de las nuevas tecnologías de información y comunicación (TIC) en el ámbito familiar y educativo.

Esta investigación ha pretendido ser un acercamiento al uso educativo que permiten y desprenden los videojuegos al tratar de explicar cómo este tipo de ocio puede llegar a ser una útil herramienta desde su dimensión educativa.

Para nosotros, los videojuegos son la versión tecnológica moderna del juego tradicional en donde los usuarios adquieren diversas habilidades, es decir, destrezas motoras, gran información verbal, destrezas intelectuales, actitudes y estrategias cognoscitivas.

También sirven para adquirir aprendizajes de tendencia social, ya que el juego en sí es sumamente interactivo y participativo, puesto que es "inmersivo"45.

En su variada tipología, hemos destacado los videojuegos de simulación por ser los más inmersivos, donde la clave reside en la activa participación del usuario ya que forma parte la vida digital.

En la segunda parte de esta investigación, hemos aplicado la teoría a un caso práctico, como el aprendizaje del Mundo clásico a partir del videojuego de “La Odisea, la búsqueda de Ulises”.

Lo primero que nos hemos planteado es si el empleo de videojuegos contribuye a la experiencia significativa del alumno, luego cómo podemos guiarle para que adquiera dichos contenidos a través de estas nuevas herramientas y finalmente cómo hacer para que el alumno sea capaz de transferir dichos conocimientos asimilados a otras áreas.

\footnotetext{
${ }^{44}$ J. Borras, A.Colomer, J.Ferrés, entre otros muchos.

${ }^{45}$ En el alumno se provoca, como dice Gibson una "alucinación consensual" donde los jugadores toman decisiones en tiempo real con repercusión virtual.

http://www.ucm.es/info/especulo/numero31/ciberwow.html
} 
En Propuestas temáticas/iconográficas para el estudio de "La Odisea” en las aulas hemos extraído multitud de divertidas actividades educativas derivadas de la obra y el videojuego para facilitar el aprendizaje en profundidad de la época griega.

En la investigación hemos hecho hincapié en la complementariedad de los videojuegos con la enseñanza de grandes textos de la Literatura Universal. La meta, en todo caso ha sido el hacer que el alumno sea capaz de interrelacionar los contenidos y estrategias educativas adquiridas a otras áreas.

Por último, destacamos la importancia de la actividad del profesor o moderador para que sea un guía a través de este tipo de ocio y emplee los videojuegos de forma controlada y responsable.

Como decíamos al comienzo del artículo, nuestro objetivo es aprender a maximizar la eficacia a través de la diversión, sin restar importancia a las tareas que nos hacen madurar como humanos: aprender y enseñar.

\section{Bibliografía}

Fuentes directas:

- HOMERO, “Odisea”. Madrid. Cátedra.

- “Ulises 31 ”, dibujos animados.

- “La Odisea, la búsqueda de Ulises”. CRYO. PC

Fuentes indirectas y generales

\section{OBRAS}

- AGUIRRE, Joaquín. “Ciberespacio y comunicación: Nuevas formas de vertebración social en el siglo XXI” (2004). Revista Espéculo.

- “Corpus digitalis. Semióticas del mundo digital” (2004). Revista DeSignis. Gedisa.

- DE MAN, Paul (1991). “Visión y Ceguera, ensayos sobre la crítica de la retórica contemporánea”. Universidad de Puerto Rico.

- “Didáctica de Lengua y Literatura, formación de profesores de educación secundaria” (2005).

Madrid. ICE. 
- IHDE, Don (2004). “Los cuerpos en la tecnología: nuevas tecnologías. Nuevas ideas de nuestro cuerpo”. Colección Nuevas tecnologías y sociedad. UOC.

- LEIBRANT, Isabella (2006). “Las herramientas electrónicas en la didáctica de la literatura”. Tesis doctoral inédita por la Universidad de Navarra.

- MALDONADO, Tomás (1999). “Lo real y lo virtual”. Barcelona. Gedisa.

- MALDONADO, Tomás (1998). “Crítica de la razón informática”. Barcelona. Paidós Ibérica.

- MURRAY, Janet. (1999) “Hamblet en la Holocubierta”. Barcelona. Paidós Ibérica.

- QUÉAU, Philip (1995). “Lo virtual: Virtudes y vértigos”. Barcelona. Paidós Ibérica.

- RYAN, Marie-Laure (2004). “La narración como realidad virtual. La inmersión u la interactividad en la literatura y en los medios electrónicos”. Barcelona. Ediciones Paidós Ibérica.

- SÁNCHEZ , Jordi (2004). “Realidad Virtual. Visiones sobre el ciberespacio”. Festival de Sitges.

- SÁNCHEZ, Primitivo (2005). “El proceso de enseñanza y aprendizaje”. Madrid. ICE.

- STOLL, David. (1999) “High Tech heretic-reflexions of a computer contrarian”.

\section{PÁGINAS WEB}

- Gagné, 1985. Gagné, Briggs and Wager, 1992. http://www.lsda.org.uk/files/PDF/1529.pdf

- Proyecto Becta. www.becta.org.uk

- Games for Learning: Are schools ready for what's to come?

http://www.gamesconference.org/digra2005/viewabstract.php?id=47

- http://es.wikipedia.org/wiki/Aprendizaje

- http://en.wikipedia.org/wiki/Edutainment

- Ciberjuego y sociabilidad:Relaciones y efectos en los usuarios de juegos online (Word of Warcraft). Belén Mainer Blanco. http://www.ucm.es/info/especulo/numero31/ciberwow.html

- http://www.dearqueologia.com

- Estudios e informes de Adese. http://www.adese.es/web/main.asp

- http://alerce.cnice.mecd.es/ mcui0001/indice.html;

- http://www.elhuevodechocolate.com/odisea1.htm;

- http://adigital.pntic.mec.es/ aramo/lectura/lectu52b.htm

- http://sepiensa.org.mx/contenidos/2004/irene/huizinga/huizinga.html http://www.javeriana.edu.co/Facultades/C_Sociales/Facultad/sociales_virtual/publicaciones/arena/hu izinga.htm

- http://es.wikipedia.org 
- http://www.answers.com/topic/quest

- http://www.portalplanetasedna.com.ar/mitologia_griega1.htm\#poseidon

- http://www.culturaclasica.com/cultura/viajes_ulises.htm

\section{CINE}

- “Atrapado en el tiempo” (1993), dirigida por Harold Ramis.

- “The Odyssey” (1997), dirigida por Andrei Konchalovsky.

- “Ulises 31” (1981). Tokyo Movie Shinsa.

\section{VIDEOJUEGOS}

- World of Warcraft. Blizzard. 2004. PC CD-Rom.

- Caballeros de la Antigua República. Bioware. 2003. Microsoft. Xbox.

- Fable. Lionhead. 2004. Microsoft. Xbox.

- Gran Thieft Auto: San AndreasRockstars Games. 2004. Microsoft. Xbox.

- Diablo II. Blizzard. 2000. PC CD-Rom.

- “DA VINCI Experience”. Nobilis, Mzone Studio, Kheops Studio, Elektrogames. 2006. PS2.

- "El Secreto de Nautilus" 2002. CRYO. PC

- “La Odisea, la búsqueda de Ulises” 2000. CRYO. PC

- "Atlantis" 2002. CRYO. PC

- "Egipto" 2000. CRYO. PC

- “Guerras Persas” 2002.CRYO. PC

- “Sahel Zone”. PC, juego experimental.

- “Oblivion”. Take 2 Interactive. 2006. Microsoft. XB360. 